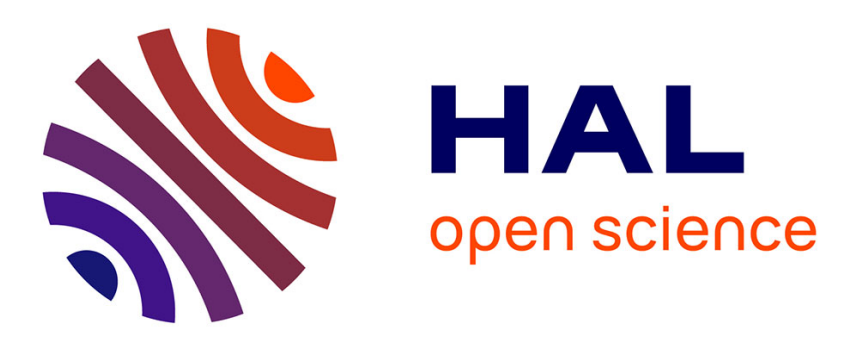

\title{
Agents' Coalition for Collaborative Workflow Orchestration of Patient Pathway in the Pediatric Emergency Department
}

\author{
Sarah Ben Othman, Faten Ajmi, Hayfa Zgaya, Slim Hammadi
}

\section{- To cite this version:}

Sarah Ben Othman, Faten Ajmi, Hayfa Zgaya, Slim Hammadi. Agents' Coalition for Collaborative Workflow Orchestration of Patient Pathway in the Pediatric Emergency Department. FLINS2016, Aug 2016, ROUBAIX, France. hal-01724377

\section{HAL Id: hal-01724377 \\ https://hal.science/hal-01724377}

Submitted on 6 Mar 2018

HAL is a multi-disciplinary open access archive for the deposit and dissemination of scientific research documents, whether they are published or not. The documents may come from teaching and research institutions in France or abroad, or from public or private research centers.
L'archive ouverte pluridisciplinaire HAL, est destinée au dépôt et à la diffusion de documents scientifiques de niveau recherche, publiés ou non, émanant des établissements d'enseignement et de recherche français ou étrangers, des laboratoires publics ou privés. 


\title{
AGENTS' COALITION FOR COLLABORATIVE WORKFLOW ORCHESTRATION OF PATIENT PATHWAY IN THE PEDIATRIC EMERGENCY DEPARTMENT
}

\author{
SARAH BEN OTHMAN, FATEN AJMI, HAYFA ZGAYA, SLIM HAMMADI \\ Ecole Centrale de Lille, Avenue Paul Langevin \\ Villeneuve d'Ascq, 59650, France
}

\begin{abstract}
In healthcare systems management, control of hospital flows and anticipation of overcrowding situations are major issues. The purpose of this paper is to contribute to the scheduling and orchestration of multi-skill health care tasks to manage bottlenecks in the Pediatric Emergency Department (PED). Our solution integrates a collaborative workflow approach to model the patient journey in order to identify dysfunctions and peaks of medical staff activities within the PED. The dynamic and uncertain aspect of the problem has led us to adopt an alliance between the Multi-Agent Systems (MAS) and workflow approach for the optimization of the health care process.
\end{abstract}

\section{Introduction}

In the management of health care systems, control of hospital flows and anticipation of overcrowding situations are major issues. Health care actors must control peaks of activity and service bottlenecks which can occur at the Emergency Department (ED) and are related to random patient flows. Today the real problem of health facilities is the unexpected influx of patients in the ED. This is the main challenge of our work. The experimental field of our study is the Pediatric Emergency Department (PED) of the Regional University Hospital of Lille. In this department, patients wait for long hours (sometimes more than 10 hours) before treatment and currently there are no tools to manage patients in case of an overcrowding situation in the PED, and no concrete measures have been adopted to solve this problem. Our work is a part of the national project HOST and discusses the emergency handling system. We focus in this work on the optimization of patient pathway and health care process in the PED. In fact, In the PED we noticed that information circulates poorly between the medical staff members, is sometimes missing or arrives late which makes problems and endanger the health of patients. Therefore, we use an original alliance between workflow and Multi-Agent Systems (MAS). The workflow methodology combined with MAS has proved its efficiency in improving health processes [1]. The workflow models efficiently patient journey and MAS optimize the orchestration of this workflow taking into account the different disturbances which may daily occur in the PED. Performance indicators are then generated to determine the efficiency of patients' management. Information delivery, waiting times and interaction with providers are the strongest significant predictors of the 
satisfaction of parents and patients who need to be continuously informed about the treatment progress.

\section{Integration of Workflow and ABS to Improve the Functioning of the ED}

There are some major barriers in the implementation of Agent-based Systems (ABS) to model the ED. One of these barriers is that human behavior is hard to model. The collection of data on human behavior can take a long time. Other barriers, such as lack of representation of common methods for implementing the $\mathrm{ABS}$ are also mentioned in the literature [2]. The integration of workflow and ABS can help to exploit the advantages of both methods. The workflow provides an environment and operating rules for agents. ED environments can be analyzed using the workflow for the orientation of patient flows at the ED and ABS for human decision making. In ABS, the behavior of the model is produced by the outcome of agents' interactions [3]. However, in a workflow model, attributes of patients are generated according to their treatment process and their mode of arrival, the processing time is generated based on the attributes of patients using the tool provided by the simulation software. Health care operations in the ED are performed according to the preset conditions and related processes. In an ABS model, operations may be dynamically determined by agents using the process of human decision making. The main idea of our research is that the use of workflow alone is insufficient to model patients and medical staff behaviors. We therefore propose an alliance between workflow and ABS. This alliance allows us to simulate the potential flow in the workflow model while being monitored by agents. In fact, information flows and decisions of the system emerge as the natural instantiation of behaviors and interaction mechanisms in ABS. A patient treatment may require a series of interactions and decision-making between patients and medical staff which are a function of the system status and reflects the perception of patients and staff, and therefore difficult to model in priori using only the workflow.

\section{Proposed Workflow and Agent-based Architectures for the PED Modeling}

\subsection{Agent-based architecture for modeling the PED actors}

With a descending approach, we designed an architecture formed by several types of agents: Home Agent (AA), Identifier Agent (IdA), Scheduling Agent (SA), 
Tracking Agent (TA), Resource Agent (RA), Medical Staff Agent (MSA) and Integration and Evaluation Agent (IEA) [4].

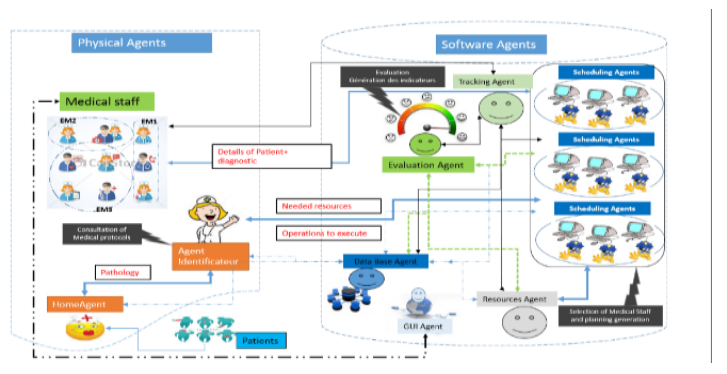

Fig. 1. The proposed agent-based architecture

In this architecture (Fig. 1), there are several types of functional agents: HA for the reception and orientation of the patient and also for the identification of pathology. After registration, it sends information about the patient to the TA which is responsible for monitoring the health condition and location of patients, and to the IdA, which defines the resources needed to treat patients and health care skills required for each task. IdA then notifies the RA and SA with information about the human and material resources to be allocated. During the process of allocation of human resources, SA communicates with MSA to identify the medical staff able to provide care for a specific patient. This is related to their skills and availability. During the execution of planning, patients with a high urgency degree have priority. Once the planning is completed, the IEA generates performance indicators for the overall assessment of scheduling generated [4].

\subsection{Agent-based Collaborative Workflow Modeling of Patient Journey in an Overcrowding Situation}

During periods of peak activity, the PED service switches into a new phase of operation, which we call "overcrowding situation". The objective is always to streamline patient flow. During peaks of activity, doctors take the initiative to commandeer all available resources, whatever their theoretical characteristics in order to meet the needs of patients. Therefore the resource "room" or "bed" or even some human resources can be "de-specified" during some tasks. For example, a consultation takes place normally in a box may be carried out in a plaster room. After several meeting and interviews with the medical staff of the PED of RUH of Lille, we have designed the following workflow model which has already been validated (Fig. 2). 


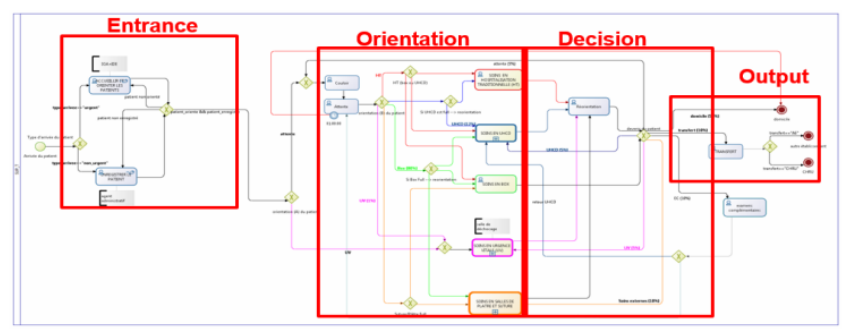

Fig. 2. PED processes management in an overcrowding situation

This model indicates the major stages, activities and actions of the patient pathway at the PED. There are four main stages: Stage 1, (Patient Arrival and Initial Assessment), Stage 2, (Patient orientation), Stage 3 (Decision making) and Stage 4 (Output and reorientation of patients). The patient can be orientated or reoriented to one of the following units modeled by a sub-process in the global workflow model: Box Unit (BU), corresponding to an In-cubicle treatment, Subprocess External Care Unit (ECU), Traditional Hospitalization Unit (THU), Subprocess Vital Emergency care Unit (VEU) and Sub-process Unit of Short Term Hospitalization (USTH).

We note that some activities of these processes are decisional. These decisions which are the result of agents' coalitions to orchestrate and re-orchestrate patients are expressed in the workflow model by six Synchronization Points called gateways, in the Fig. 2. These points are used to control and manage patient flows behavior. The decision points $\mathrm{DP}_{\mathrm{i}}(1 \leq \mathrm{i} \leq 6)$ of the global workflow model are detailed as follows:

DP1: displays how the patient arrives at the PED. In case of an urgent situation, he goes directly to the reception desk. Otherwise he goes to the registration one.

$\mathbf{D P}_{2}$ : controls the registration and the orientation of the patients.

$\mathbf{D P}_{3}$ : it is a phase of orientation of the patient to vital emergency or waiting room.

DP4: this point is central because it characterizes the beginning of a bottleneck in the global model. It orientates patients to the suitable unit care depending on their pathologies.

DP $_{5}$ : this point is important because it represents the ending of the bottleneck point. Depending on decision taken by agents, patients are directed to the waiting room, other units, Complementary Exams Unit (CEU) or Home.

DP6: after the complementary exams, the coalition of agents is created in order to dynamically re-orchestrate patients in order to reduce their waiting time. These 
decisions need a negotiation process within the coalition taking into account the treatment characteristics and the availability of physical resources.

\section{Simulations and results}

The PED of RUH of Lille has provided real data collected over a period of 3 years: 2011-2012-2013. For the simulation, we chose a scenario of a real overcrowded day which occurred at the PED in the $7^{\text {th }}$ of February 2013. During this day, the PED has received about 119 patients that have generated the most outstanding peaks of the year. The difficulty is to smooth the peaks of activity and reduce the waiting time of patients. To start the simulation, we define an incoming flow of patients and we specify the resources necessary for the execution of health care tasks taking into account the skills of medical staff and the availability of resources.

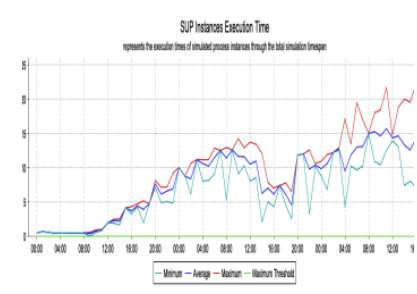

Average waiting time with static orchestration

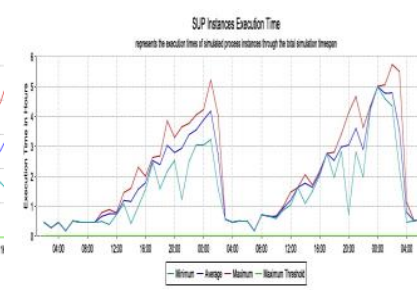

Average waiting time with dynamic orchestration

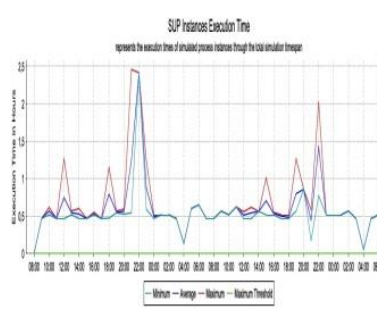

Average waiting time with reorchestration

Fig. 3. PED processes management in an overcrowding situation

The results show curves which indicate the overall minimum, maximum and average waiting time of patients at the PED. We present first the results given by the SA which has the role of a scheduler using a scheduling algorithm developed in our previous work [5] with static orchestration. Then we show that the SA communication with other agents in order to dynamically orchestrate workflow of the patient journey has reduced waiting times. From the first curves in Fig.3, we note that during the overcrowding day, the average waiting time diverges. The average wait is estimated at 10 hours. The medical staff is thus unable to cope with the increasing flow of patients arriving at the PED. The second curves show that the optimization approach based on the alliance between the workflow approach and MAS helped to smooth the peaks of activity at the PED and minimize the overall average waiting time of patients. Indeed, the SA acts as an orchestra leader, it coordinates its actions with other agents to ensure a dynamic orchestration adapted to the real situation of the PED. In this case, the waiting time varies between 1 hour and 4 hours. However, we note that there is always a 
peak of activity at midnight disrupting the PED. The previous orchestration actions have not managed to absorb all the PED peaks of activities. So, we employ negotiation between agents in the coalition formed to dynamically re-orchestrate the workflow of remaining patients' pathways. This negotiation is based on the results of additional tests (biological tests, MRI, etc.) for taking decision about patients' orientation. The results obtained from the dynamic orchestration are presented in the last curves in Fig.3. The average waiting time is reduced and the average varies between $30 \mathrm{~min}$ and $2 \mathrm{~h} 30 \mathrm{~min}$ with a peak between $18 \mathrm{am}$ and 00 pm.

\section{Conclusion}

In this paper, we have proposed an alliance between a workflow approach and a multi-agent architecture that provides a solution for managing collaboration between medical staff dynamically in the PED. The use this alliance for process management within a health care institution is widely accepted today. However, its use in the context of inter-hospital still faces some challenges, the most important are the difficulty of the patient's file transfer between different services and the lack of standardization in the interconnection of the various local workflows. This will be the interest of our future work.

\section{References}

1. Ducq Y, Vallespir B, Doumeingts G. Utilisation de la méthodologie GRAI pour la modélisation, le diagnostic et la conception d'un système hospitalier. 2ème conférence francophone en Gestion et Ingénierie de Systèmes Hospitaliers (GISEH). Mons; 2004.

2. Escudero-Marin, Paula, et Michael Pidd. «Using ABMS to Simulate Emergency Departments ». Proceedings of the Winter Simulation Conference. Phoenix, Arizona: Winter Simulation Conference, 2011. 12391250. ACM Digital Library. Web. 25 sept. 2015. WSC '11.

3. Cabrera, Eduardo, Manel Taboada, et al. «Simulation Optimization for Healthcare Emergency Departments ». Procedia Computer Science 9 (2012): 1464-1473. ScienceDirect. Web. Proceedings of the International Conference on Computational Science, ICCS 2012.

4. Ben Othman S., Zoghlami N. Hammadi S., Quilliot A., Muli-objective Evolutionary for Multi-Skill Health care tasks Scheduling, in proceedings of the $15^{\text {th }}$ IFAC/IEEE/IFIP/IFORS Symposium/ Information Control Problems in Manufacturing (2015), Ottawa, Canada. 